Original Research Article

\title{
Drug utilization study-pattern of use of anti-microbial drugs among post operative patients in department of general surgery at a tertiary care hospital
}

\author{
Dhwani J. Patel*, Sunita B. Chhaiya, Dimple S. Mehta
}

Department of pharmacology, C. U. Shah Medical College and Hospital, Surendranagar, Gujarat, India

Received: 24 March 2017 Accepted: 05 April 2017

*Correspondence to: Dr. Dhwani J. Patel, Email: djp1712@gmail.com

Copyright: (C) the author(s), publisher and licensee Medip Academy. This is an openaccess article distributed under the terms of the Creative Commons Attribution NonCommercial License, which permits unrestricted noncommercial use, distribution, and reproduction in any medium, provided the original work is properly cited.

\begin{abstract}
Background: The objective of this study was to assess the current trends of prescribing antibiotics amongst the patients of General surgery postoperative unit of C. U. Shah Medical College and Hospital, Surendranagar, Gujarat.

Methods: An observational study was done amongst 200 patients admitted in the General surgery postoperative ward of a C. U. Shah Medical College and Hospital, Surendranagar over a period of 6 months in accordance with the ethical principles of the ethics committee guidelines. Data were analyzed using Microsoft Office Excel 2007 and values were presented descriptively in percentiles.

Results: The average number of antimicrobials per encounter was 1.78. The most common surgeries in the postsurgical unit were urological procedures 61 $(30.35 \%)$ followed by incision and drainage 40 (20\%). Most of the patients were in the age group of 35-60 yrs. Higher utilization of cephalosporins $(62.91 \%)$ and fluoroquinolones $(20.27 \%)$. The most preferred route of administration of antibiotics in post operative period was oral (55.58\%).

Conclusions: The present study provides valuable insight about the overall pattern of anti-microbials used in postoperative patients in a tertiary care hospital. It is intended to be a step in broader evaluation of safety and efficacy of drug as well as for improving prescribing habits among the fraternity and minimizing incidence of resistance to antimicrobials in surgical wards of a teaching hospital.
\end{abstract}

Keywords: Antimicrobials, General Surgery, Post-operative

\section{INTRODUCTION}

Drug utilization research was defined by WHO in 1997, as "the studies of marketing, distribution, prescription and use of drugs in a society, with special emphasis on the resulting medical, social and economic consequences. ${ }^{1}$ The principle aim of drug utilization study is to encourage rational use of drugs. Monitoring of prescriptions and drug utilization studies can help to identify the problem associated with prescribing and also help provide feedback to the prescribers. ${ }^{2}$

Antibiotics are one of the pillars of modern medical care and play a major role both in the prophylaxis and treatment of infectious diseases. ${ }^{3}$ The use of antibiotics to prevent infections at the surgical site is known as the surgical antibiotic prophylaxis. It is an effective management strategy for reducing postoperative infections, provided that appropriate antibiotics are given at the correct time for appropriate durations and for appropriate surgical procedures. ${ }^{4}$ As per Kunin's criteria it was observed that $64 \%$ of total antibiotics prescribed were either not indicated or inappropriate in terms of drug or dosage. ${ }^{5}$ Inappropriate and indiscriminate use of antimicrobial agents can potentially have a number of problems including emergence of antimicrobial resistant bacteria. Information about patterns of usage of antimicrobial drugs is necessary for a constructive 
approach to problems that arise from the multiplicity of antibiotics now available. Hence calls the need to carry out antimicrobial drug utilization studies.

\section{METHODS}

This study was designed to evaluate the pattern of antimicrobial prescription in post operative indoor patients of General Surgery Department at C. U. Shah Medical Hospital, Surendranagar.

This observational cross-sectional study was carried out over a period of six months.

All the patients who had undergone any surgical procedure and were admitted to the indoor ward were included in this study. Those patients who died on table or in post-operative period before being discharged, those absconded or discharged against medical advice or who were refer to higher center were excluded from the study. The demographic, clinical and prescribing information was collected from patient's case record sheet in a prestructured case report form by visiting the department regularly. All the included patients were followed till discharge. The collected data was analyzed for the following parameters:

- Number of antimicrobials per prescription

- Number of antimicrobials prescribed by generic name or brand name

- Type of antimicrobial used and preferred route of administration

- Number of prescriptions with mono-therapy or two drug therapy or multi drug therapy

\section{RESULTS}

Total 1351 prescriptions of 200 post-operative patients in General surgery department were analyzed over a period of six months. The demographic data of the patients has been shown in Table 1 .

Table 1: Demographic characteristics $(\mathrm{N}=\mathbf{2 0 0})$.

\begin{tabular}{|lll|}
\hline Age & $\begin{array}{l}\text { Number of } \\
\text { patients }\end{array}$ & $\begin{array}{l}\text { Percentage of } \\
\text { patients }(\%)\end{array}$ \\
\hline 0-20yrs & 52 & \\
\hline $21-40 y r s$ & 56 & 26 \\
\hline $41-60 y r s$ & 65 & 32.50 \\
\hline$>60 y r s$ & 27 & 13.50 \\
\hline Total & 200 & \\
\hline Gender & & \\
\hline Male & 125 & 62.50 \\
\hline Female & 75 & 37.50 \\
\hline Total & 200 & \\
\hline
\end{tabular}

The average number of antimicrobial prescribed per prescription was 1.78 . In $50.5 \%$ of prescriptions antibiotics were prescribed as mono-therapy and $49.5 \%$ antibiotic prescriptions had fixed drug combinations. Among the fixed drug combination therapy $28 \%$ were three drug combinations followed by $21 \%$ of prescriptions were two drug combination and only $1 \%$ of prescription had multi drug combination (Figure 1).

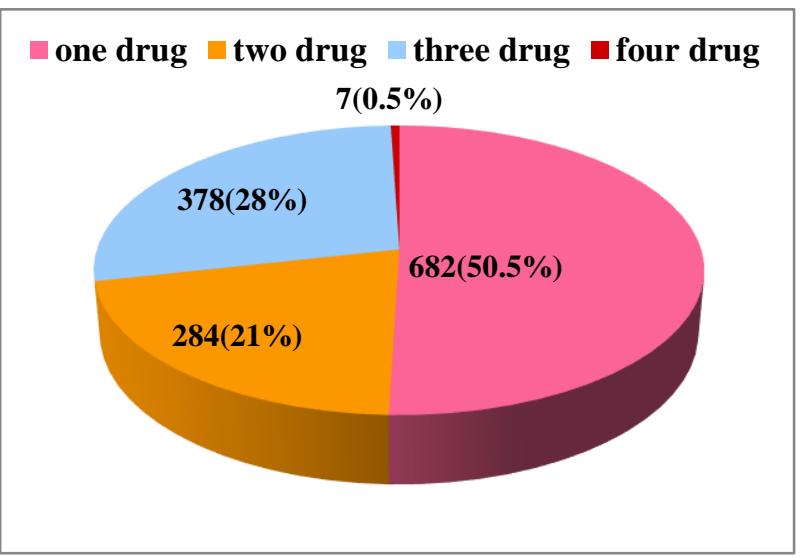

Figure 1: Number of antimicrobial used per prescription (one, two, three, four) $(\mathrm{N}=1351)$.

The most commonly used antimicrobial in postoperative period was Cephalosporins in $62.91 \%$ prescriptions followed by Fluoroquinolones in $20.72 \%$ prescriptions. The pattern of utilization of antimicrobial agents according to their class has been shown in Table 2 .

Table 2: Prescribing pattern of antimicrobials according to their class $(\mathrm{N}=1351)$.

\begin{tabular}{|lll|}
\hline Drug Group & $\begin{array}{l}\text { Number of } \\
\text { prescription }\end{array}$ & $\begin{array}{l}\text { Percentage of } \\
\text { Prescription (\%) }\end{array}$ \\
\hline Penicillins & 105 & 7.07 \\
\hline Cephalosporins & 850 & 62.91 \\
\hline Nitroimidazoles & 85 & 6.29 \\
\hline Aminoglycosides & 30 & 2.22 \\
\hline Fluoroquinolones & 280 & 20.72 \\
\hline Macrolides & 1 & 0.07 \\
\hline Total & 1351 & \\
\hline
\end{tabular}

Table 3: Prescribing parameters of antimicrobials ( $N=1351)$.

\begin{tabular}{|lll|}
\hline Characteristics & $\begin{array}{l}\text { Number of } \\
\text { prescription }\end{array}$ & $\begin{array}{l}\text { Percentage of } \\
\text { prescription (\%) }\end{array}$ \\
\hline Generic name & 264 & 19.54 \\
\hline Brand name & 1087 & 80.50 \\
\hline Route of administration & \\
\hline Oral & 751 & 55.58 \\
\hline Intravenous & 600 & 44.41 \\
\hline
\end{tabular}

The most preferred route of administration was oral in $55.58 \%$ prescriptions. It was observed that majority of 
drugs were prescribed by brand names. The detail of the prescribing parameters has been shown in Table 3 .

Figure 2 shows distribution of patients according to different types of surgeries. Most common surgeries were observed as urological procedures $(30.5 \%)$.

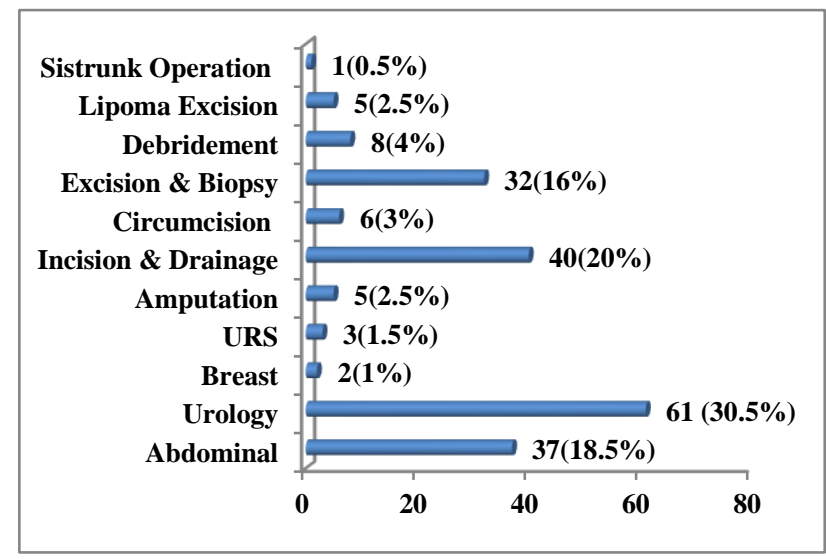

Figure 2: Distribution of patients undergoing different types of surgery $(\mathrm{N}=\mathbf{2 0 0})$.

Figure 3 shows distribution of patients according to duration of hospitalization.

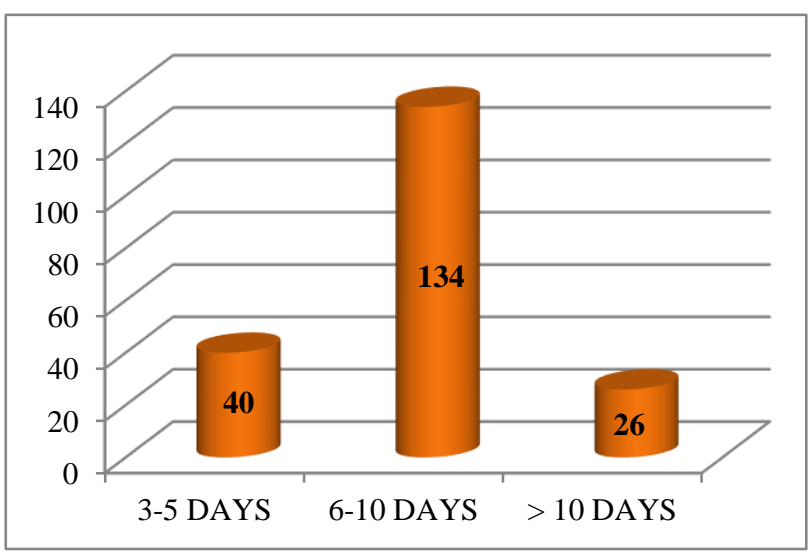

Figure 3: Distribution of patients according to duration of hospitalization.

\section{DISCUSSION}

Antimicrobial agents are very important class of drugs which are essential in treating or preventing development of infections in patients. Patients in surgical wards develop infections post surgery; many of the infections are caused by bacteria that are highly virulent. As a result, there is a need for prophylactic or empirical treatment with antimicrobial agents that can cover broad spectrum of pathogens.

This study provides an overview of total antimicrobial use in General surgery department of a tertiary care teaching hospital. It is observed that majority of patients were between the age group of 21 and 60 years, total 121 cases $(60.5 \%)$. In the present study, the average number of antimicrobials used for prescription was 1.78 in comparison to a study by Sapna et al, were average number of antibiotics per prescription was 2.5 .

In this study, the top most frequently used antimicrobials were Cephalosporins $(62.91 \%)$ followed by Floroquinolones $(20.73 \%)$ and Penicillins $(7.77 \%)$. This was consistent with the pattern of antimicrobial use observed in other study conducted by Venkateshwar et al in India. ${ }^{6}$ In the present study, $50.5 \%$ prescriptions had antimicrobial prescribed as mono-therapy, and $49.5 \%$ prescriptions had more than one antimicrobial, which was in contrast to study conducted by Venkateshwar et al and Sapna et al. ${ }^{6,7}$ Surgical procedures needs antimicrobial coverage to avoid postoperative infective complications. These different combinations of antimicrobials have every possibility of producing more adverse reactions, increase resistance and in addition increased costs of the therapy to the patients concerned as well as to the health care system. In the present study, $80.50 \%$ antimicrobials were preferred by brand names. This trend was similar with Khade et al. ${ }^{8}$ Writing prescriptions using generic name is an important drug-use quality to avoid undesirable drug interactions, adverse drug reactions, and medication errors. In this study, majority of drugs were prescribed as brand names. Use of generic names for prescribing was seen only in $19.54 \%$.

\section{Limitation}

The number of cases in the present study might not be sufficient to represent the overall prescribing pattern where the repeated prescription audit is necessary to assess changes in the prescribing behaviour.

\section{CONCLUSION}

The present study revealed that the use of poly pharmacy and branded drugs are common. So, it is needed to have antimicrobial policy at institute level. The trend of antimicrobial use in surgical departments is necessary to evaluate the effectiveness of interventions. There is a clear need for the development of prescribing guidelines and educational initiatives to encourage the appropriate use of antimicrobials in post-surgical period. Also, there is scope for improving prescribing habits among the fraternity and minimizing incidence of resistance to antimicrobials.

\section{ACKNOWLEDGMENTS}

Authors would like to acknowledge the Physicians, Professors and resident doctors of the Department of Pharmacology and Surgery of C. U. Shah Medical College, Surendranagar for supporting the respected study.

\section{Funding: No funding sources \\ Conflict of interest: None declared}


Ethical approval: The study was approved by the Institutional Ethics Committee of C. U. Shah Medical College and Hospital, Surendranagar, Gujarat, India

\section{REFERENCES}

1. WHO Expert Committee. Introduction to drug utilization research, World Health Organization: Geneva, 2003. Assessed on 25-07-2013.

2. DG Shewade, SC Pradhan. Indian J. Pharmacol. 1998;30:408-10.

3. Teferra A, Mohammed K. The pattern of antibiotic usage in surgical inpatients of a teaching hospital, Northwest Ethiopia. Etiop J Health Dev. 2004;18(1):35-8.

4. Munckhof W. Infectious Diseases Physician and Clinical Microbiologist, Princess Alexandra Hospital, and Senior Lecturer in Medicine, University of Queensland, Brisbane, Antibiotics for surgical prophylaxis, Aust Prescr. 2005;28:38-40.
5. Kunin CM. Rational use of antibiotics. WHO Drug Information. 1990;4(1):4-7.

6. Venkateshwar. Drug utilization study of antibiotics in surgical ward of a tertiary care hospital. International Journal of Chemical and Pharmaceutical Sciences. 2015 Mar;6(1).

7. Sapna P, Padma L, Veena DR, Shanmukananda P. Drug utilization study of antimicrobials in postoperative wards in a teaching hospital. Int Res J Pharm App Sci. 2012;2(5):56-9.

8. Khade A, Bashir MS, Sheethal A. Prescription pattern in the department of surgery in a tribal district hospital of Andhra Pradesh, India. Annals of medical and health sciences research. 2013;3(3):438-41.

Cite this article as: Patel DJ, Chhaiya SB, Mehta DS. Drug utilization study-pattern of use of antimicrobial drugs among post operative patients in department of general surgery at a tertiary care hospital. Int J Basic Clin Pharmacol 2017;6:1482-5. 